\title{
Mad cows, mad corn and mad communities: the role of socio-cultural factors in the perceived risk of genetically-modified food
}

\author{
Melissa L. Finucane \\ Decision Research, Eugene, Oregon 97401, USA
}

\begin{abstract}
The rapid globalization of the world economy has increased the need for a knowledge base of reliable socio-cultural differences in perceptions, values and ways of thinking about new food technologies. Awareness of socio-cultural differences is important because collaborative efforts to deal with food hazards presuppose some understanding of where, how and why the viewpoints of various stakeholders may differ. In the present paper factors that influence public perceptions of genetically-modified (GM) food are discussed, with a special focus on the unique circumstances of populations in the USA, Europe and developing countries. It is argued that effective communication and decision making about the risk of GM food depends critically on understanding how socio-cultural groups differ in their values and in the way they deal with the risks and benefits of new technologies. The implications of psychological aspects of perceived risk (including the roles of qualitative dimensions of risk, world views and trust) for public acceptance of new food technologies are highlighted.
\end{abstract}

Genetically-modified food: Culture: Risk perception: Psychology

The present paper examines the role of socio-cultural factors in the perceived risk of genetically-modified (GM) food. The importance of social and cultural dimensions of risk debates has been underscored already by the different perspectives that experts and lay individuals bring to the negotiating table. Members of our scientific culture have long been frustrated by the so-called irrational perspectives and behaviours that they believe are displayed by members of the lay culture. And lay individuals have often castigated scientists for their apparent lack of understanding of what is most important in decisions about potentially risky technologies. The debate about GM food has arrived on stage, however, just as the world trade economy is accelerating toward globalization. So, unlike previous debates about other new technologies, the expert-lay divide over GM food is compounded by the international context in which the technical and ethical complexities of genetic engineering (GE) are being debated.

In any domain, effective risk communication and decision making depend on understanding public perceptions of risk. And understanding public perceptions of risk depends critically on understanding the socio-cultural factors involved. Yet, many individuals involved in policy development, decision making and risk communication about GE come from backgrounds of biological science rather than social science. Knowledge gaps about other individuals' cultural values (especially values underlying perceptions of risk) make it necessary to search for a framework by which we can at least know what we don't know, and anticipate what happens when different sociocultural groups come together to make decisions about GE. The present paper shows how research from the fields of human judgement, decision making and risk perception can be drawn on to help us understand national differences in cognition and behaviour.

Interest in cross-cultural comparisons typically stems from the premise that different cultural contexts influence individuals' cognitions and behaviours. At the outset, therefore, it is necessary to define what is meant by 'cultural differences'. Commonly, cultural differences are viewed as attitudinal or behavioural divergences associated with differences in stable social structures, processes and/or values. In other words, cultural differences relate to the shaping of individual and collective behaviour by a set of common characteristics, including geography, climate, history, economics, politics and psychology (Tse et al. 1988; Weber \& Hsee, 1999). Cultural differences often follow national boundaries, although not always, as has been suggested already with the reference to scientists and lay individuals as different cultural groups. The main focus of

\footnotetext{
Abbreviations: BSE, bovine spongiform encephalopathy; GE, genetic engineering; GM, genetically modified; vCJD, variant Creutzfeld-Jacob disease. Corresponding author: Dr Melissa Finucane, present address Center for Health Research, 501 Alakawa Street, Suite 201, Honolulu, HI 96817, USA, fax +18084324785, email melissafinucane@ hotmail.com
} 
the present paper is on nations as proxies for cultures, but this approach belies the complex mix of intra-national cultures that contribute to policy development. The goal here is simply to explicate socio-cultural differences in risk perceptions and behaviours, rather than to prescribe specific policy options for any particular regions or groups.

Understanding the potential for socio-cultural differences in risk debates is important for several reasons. Perhaps most critical is the rapid globalization of the world economy, which has increased the need for a knowledge base of reliable cross-cultural differences in perceptions, values and ways of thinking. As Hofstede (1984) stresses: 'The survival of mankind will depend to a large extent on the ability of people who think differently to act together. International collaboration presupposes some understanding of where others' thinking differs from ours'. An astute cross-cultural understanding is particularly important as global trade in new biotechnologies increases and international governance policies are developed. Different cultural groups are likely to evaluate and to deal with the risks and benefits of new technologies such as GE in diverse ways because of tendencies toward different decision styles and values. As a result they may develop different risk-management policies. Cross-cultural differences in policies can create misunderstanding and conflict when trying to weigh up the complex array of health, environmental and social benefits and risks faced in the international exchange of GM foods and crops for research and commercial development or consumption.

In short, understanding cultural differences is critical for accurately interpreting information and events in different cultures, which in turn is crucial for facilitating economic and social development in a way that appropriately balances the costs and benefits of new technologies in the unique environmental and human health contexts of different countries. Insightful interpretation of information and events is also fundamental to the development of creative solutions to difficult environmental and social decisions, communications and risk-management issues.

The present paper begins with some background to the role of socio-cultural factors as determinants of public risk perceptions. Then, cross-national differences in reactions to GE are examined. Finally, cultural theory and the implications of individual differences in world views are discussed.

\section{Understanding risk}

Traditional solutions to conflicts over the risks of new technologies have often involved calls for better technical analysis and expert oversight via small centralized groups charged with creating uniformity and rationality in highly technical areas of risk management. Proponents of this approach argue that an expert group is needed to ensure that regulations are based on 'sound science' and effectively reduce significant risks at reasonable costs. This approach reflects the traditionally narrow view of risk, which customarily defines risk as 'the chance of injury, damage or loss' (Webster, 1983).

Recently, however, social scientists have rejected this notion of 'real' or 'objective' risk, and argue instead that risk is inherently subjective (Krimsky \& Golding, 1992; Slovic, 1992); i.e. risk cannot be measured 'out there', independent of our minds and cultures. Rather, risk is a social construct, meaning different things to different individuals. While technical analysis is vital for informed and accountable risk decisions, trying to address risk controversies primarily with more science that fails to reflect the context-dependent and culturally-dependent nature of risk is likely to exacerbate conflict (Slovic \& Gregory, 1999).

Several decades of psychometric research (see Slovic, 1987) have shown that public conceptions of risk are complex and guided by qualitative features of hazards, or what could be called the 'personality' characteristics of hazards. In essence, there are two main qualitative dimensions that seem to drive risk perceptions: unknown risk (known $v$. unknown); dread risk (not dreaded $v$. dreaded). The unknown risk factor reflects the extent to which a hazard is unknown, unobservable, unfamiliar and has delayed consequences. The dread risk factor reflects the extent to which a hazardous activity or technology is seen as dreaded, uncontrollable, fatal, not equitable, high risk to future generations, not easily reduced, involuntary and has catastrophic potential.

One illustration of the importance of unknown and dread characteristics in the perception of food risks comes from the case of British beef. Since the mid-1990s British beef has had features of unknown risk through its association with 'mad-cow' disease or bovine spongiform encephalopathy (BSE) and variant Creutzfeld-Jacob disease (vCJD) in man. Many aspects of BSE in general, and the relationship between BSE and vCJD in particular remain unclear. Science still does not understand BSE or vCJD adequately (there is still no readily-available vaccine or cure for either prion), and farmers and suppliers often do not know what parts of animals may end up in the feed or supplements given to cows, let alone to human subjects. Further, the effects of a disease such as BSE in cows or vCJD in human subjects are latent and not easily observed at first (Granot, 1999).

British beef also has elements of high dread risk; individual consumers cannot easily control the spread of contamination, and symptoms of BSE and VCJD are horrific and potentially fatal. The risk is also involuntary; unless recipients make their own meat products from their own cows they know have not been fed anything containing the meat, bone, fat or nervous tissue derived from other ruminants, they have little choice in the matter (except to stop eating beef and beef products altogether). Also, the meat used in human food products seems to come from an uncontrollable source; i.e. meat is delivered by strangers, and is processed, stored and distributed by large companies, none of which can be influenced to any great extent by an individual consumer.

Similarly, public opposition to GM foods can be understood from what we know about characteristics of hazards that lead to high risk perceptions. Consider how GE appears on unknown and dread risk characteristics. First, GE presents unknown risk. To some individuals GM foods seem very risky because they are based on relatively new science (so scientists do not have enough knowledge to 
estimate the risks accurately). Furthermore, the inadvertent introduction of harmful changes in DNA structure is not immediately obvious (the effects are delayed). And finally, consumers do not necessarily know when they are exposed, because they are not well-informed about which products contain GM ingredients and GE is not obvious to the casual observer. In contrast, GM medicines are seen as less risky because they are targeted at a very specific audience who is likely to be well informed (by someone considered trustworthy, such as a primary-care doctor) and expecting an observable effect (Marris, 2000).

GM foods also have features of dread risk. Food growers are the ones who decide whether to use GM seeds or other products, so consumers do not necessarily have a choice (involuntary exposure). Many individuals are exposed to GM foods (signalling global catastrophic potential), and the risks and benefits are not fairly distributed (currently the benefits are greatest for farmers and GM food manufacturers rather than consumers). Furthermore, children are heavy consumers of some products (e.g. milk), making parents especially sensitive to potential harm to future generations. In contrast, GM medicines have less dread risk associated with them because exposure is usually voluntary and some potential benefit to the patient is anticipated.

In short, while scientists may measure risk primarily as a function of probability, public perceptions of risk incorporate many other non-technical factors (Slovic, 1987).

\section{Benefits, risks, trust and decisions in different countries}

\section{The trans-Atlantic debate}

The sharpest policy conflict regarding GE has occurred across the Atlantic, between the USA and European countries. Initially, GM foods were embraced by American consumers and farmers. The use of GE in agriculture was perceived as presenting several distinct benefits, including enhanced farming productivity, reduced pesticide use and run-off, tailored micronutrient enrichment of food and reduced food costs and other attractions for consumers. That perception changed dramatically, however, when a study published in the prestigious journal Nature suggested that GE may have harmful effects (Losey et al. 1999). Simultaneously, American farmers found that their export markets were drying up as European consumers started boycotting GM foods. Since then, the tide has turned rapidly and non-GM ingredients have been emphasised in US marketing and advertising campaigns.

In striking contrast to the initial acceptance of GM food in the USA, the history of opposition to GM products began much earlier in European countries, where there was relatively little public discussion about the results of field trials and risk-management policies. Vehement public opposition through Europe has led the EU to suspend the introduction of new GM crops pending legislation that may take several years to be finalised.

To some extent, the trans-Atlantic debate seems to have been about economic, environmental and health risks. For instance, there have been arguments about what food safety or trade restrictions to place on GM crops or products, what labelling to require and what patent protection to allow. However, a closer look suggests that there are clear signs that the trans-Atlantic debate is not only about basic health or wealth or environmental protection. Rather, the opposition in Europe to American GM exports is also determined importantly by cultural values that reflect sensitivities to dread and unknown risk.

One illustration is the effort, for instance in France, to reassert 'culinary sovereignty' in response to the erosion of traditional food and eating habits due to the invasion from America's fast food culture (Klee, 1999). If one culture is feeling invaded by another it will elicit a sense of dread risk to the extent that the invasion is uncontrollable, involuntary, a threat to future generations and inequitable (in that the risks are incurred by the invaded and the benefits are incurred by the invader).

Furthermore, the idea that transgenesis is inherently wrong has been expressed by several religious bodies who are worried that transgenesis will upset the natural order of things, unleashing unknown consequences (see Bruce \& Eldridge, 2000). For instance, GM foods are considered morally disgusting by members of the Scottish Anglican church; moving genes between species that could never breed normally is 'not natural' and likened to 'playing god' (Shepherd et al. 2000; see also Paarlberg, 2000).

Non-European groups have also expressed important concerns that the idea of GE is contrary to their belief systems. For instance, a moratorium on GM imports into New Zealand was announced in 2000, with questions being raised about unknown risks to Mäori cultures and their relationship with the environment, the involuntary nature of their exposure to new technologies and products, and the inequitable distribution of risks and benefits of imports. Concerns related to cultural impacts come from the fact that Mäori believe that to switch genes across species violates an inherent wisdom in the natural order. They are concerned about the recognition and protection of Mäori cultural, spiritual, ethical or socio-economic values, about the protection of the mauri (spiritual essence) of individuals, flora, fauna, land, waterways and air, and about the preservation of traditional Mäori knowledge.

\section{Developing countries}

While debate over the benefits and risks of transgenic or GM organisms in agriculture has been intense in the rich industrial world (primarily where biotechnology has been developed and commercialised), the greatest human and environmental impacts (good and bad) are arguably in the developing world (Levidow, 1999).

The use of GM foods and crops presents several distinct benefits to developing countries. First, remote and disadvantaged rural areas that were bypassed by the Green Revolution (due to unsuitable soil, water, topography and labour endowments) will benefit from GM crops because they depend less on the hard-to-get hard-to-manage 'packages' of purchased chemical inputs. Second, additional environmental benefits arise from reduced pesticide use through the spread of herbicide-resistant and pestresistant GM varieties, because there will be less run-off of 
pesticides into surface and groundwater, and reduced need for tillage. Third, natural rural ecosystems would be under less pressure from population-linked expansion of land area devoted to low-productivity crop farming (especially shifting cultivation) and livestock grazing. Fourth, human health will benefit. Micronutrient-rich crops can be engineered (e.g. rice can be enhanced with vitamin A to counter eye damage among the poor), and increased farm productivity will boost food production and lower the price of food staples in poor countries, increasing the consumption of food and non-food goods among the poor (Levidow, 1999).

Despite these benefits of GM foods and crops in developing countries, however, there is also potential for environmental and health risks. First, developing countries may become testing grounds for novel and potentially risky substances that they have neither the capacity nor the regulatory frameworks in place to deal with. Second, many developing countries (especially in the Asia-Pacific region, for instance) are rich in natural biological endowments and have raised concerns about the potential of GM seeds to increase the genetic uniformity of crops they grow and/or of native flora. Third, cultural diversity may be threatened as current risk analysis procedures attempt to incorporate marginalized groups into a mainstream identity. Fourth, there is potential for biohazards being created, such as insect populations becoming resistant to the toxins in GM crops or plants developing into herbicide-resistant 'superweeds'. The capacity for field testing under closely monitored conditions is potentially poorer in developing countries than in industrialized countries. Fifth, labelling requirements may be technically unattainable or unaffordable in poorer countries, thus excluding them from entering lucrative world markets for GM products that might emerge in the future (Paarlberg, 2000).

So we are left with a complex decision scenario. While a precautionary approach to the new technology, such as that followed in Europe, may be affordable in industrialized countries, the greater levels of poverty and starvation in developing countries may make too much precaution inappropriate. Furthermore, the scientific, industry-friendly approach (e.g. in the USA) may be acceptable where there is the capacity to identify and manage the tangible and non-tangible impacts of GE, but poorer technical and political capacities may make it more difficult for developing countries to pursue the benefits of GE safely and equitably (Tutangata, 1999). Given these differences, the highly precautionary European policies and the industry-friendly US policies regarding GE development and regulation may be inadequately sensitive to the unique circumstances of developing countries. Clearly, the developing world's needs and values (not the current trans-Atlantic debate) should guide the formation of policy in developing nations.

\section{Trust}

An important dimension of agency-public interaction is public trust in regulatory and management officials. Despite co-development of technologies used in modern crop improvement in the USA and Europe, the very different response of the public to GM products on the two continents may relate to different levels of trust. In the early 1990s the USA brought foods containing GM ingredients to market quickly and without labels. American farmers enthusiastically embraced GM crops and the potential benefits they brought. Discussions among scientists, regulators, farmers and environmentalists led to US field tests in the mid 1980s, from which data were shared, concerns were addressed with more experiments and then informed decisions were made (Beachy, 1999).

In contrast, there was no real central regulator in Europe to green-light the technology and allay public fears. European field tests in the early 1990s failed to engage discussions between the public and governmental agencies. Overall, the European public were not convinced by the US system of regulation and approval (Beachy, 1999), and for small farmers in particular biotechnology represented a threat rather than an opportunity.

Public trust in food safety processes probably also played a crucial role in Europe. Factors such as concern over mad-cow disease highlighted to Europeans the lack of effective and transparent regulatory oversight, and fuelled their mistrust of government and large organizations. In the UK, for instance, the government's attempt to play down the mad-cow disease crisis in the early 1990s led to trust plummeting and risk perceptions skyrocketing, paving the way for more generalized fear of food safety. Britain's 1996 bout with mad-cow disease, although unrelated to GE, weakened European confidence in regulators and industrialstrength agriculture.

The role of trust is evident in less-industrialized countries also. Research by Aerni (1999) on public opposition to GM rice in the Philippines suggests that transgenic crops are valued less in the Philippines than in the USA, partly because of a lack of confidence in the regulatory institutions that promote GE. Public debate about the acceptability of transgenic rice in the Philippines (which has one of the best capacities for agricultural biotechnology research in Southeast Asia) is strongly polarized. The new technology is not favoured by non-governmental organizations and other public interest groups, but is favoured by Filipino scientists.

Social trust (the willingness to rely on the policies and decisions of agencies and their employees) has been found to be important to the perception of environmental risks and to the acceptance of emerging technologies and environmental management practices (Earle \& Cvetkovich, 1995). A lack of trust has been cited in numerous studies as a critical factor in the gap between expert and lay assessments of risk (Slovic, 1997). Trust has also been found to be strongly linked to risk perceptions. For instance, Grobe et al. (1999) found that greater trust in the US Food and Drug Administration as a food-related information source was related to less concern about the adverse health effects from the use of recombinant bovine growth hormone. These findings suggest a direct relationship between distrust in regulatory agencies and risk perceptions.

Earle \& Cvetkovich (1995) have argued that shared values constitute the foundations of trust. If individuals' or institutions' behaviour reflects shared values the characteristics of trustworthiness will be attributed to them; the future 
behaviour of trusted individuals is expected to be guided by the shared values.

\section{Cultural theory}

The importance of culture in determining the values salient to individuals judging risk and its acceptability has been considered at length by Douglas \& Wildavsky (1982). According to these authors, perceived risk is a collective phenomenon; every cultural group chooses to attend to some risks and ignore others in order to maintain a particular way of life. Extending this argument, Dake (1991) identified distinct cultural world views (beliefs about how the world and its social structure should be organised) that are associated with particular trends in risk perceptions. For instance, groups endorsing a hierarchical world view (supporting superior or subordinate social relationships and detesting civil disobedience) tend to focus on the opportunities offered by industrial and technological risks. In contrast, groups endorsing an egalitarian world view (supporting broad distribution of power and wealth, and detesting ranked role differentiation) tend to focus on the threats presented to their social structure.

To examine the relationship between world views and risk perceptions of environmental and health hazards, two large national surveys of American samples have been conducted. Results of one survey (see Flynn et al. 1994) showed that white males tend to see the world as much less risky than do other population subgroups. For a wide range of hazards, from cigarette smoking to climate change, risk perception ratings of white males were consistently much lower than those of white females, non-white males and non-white females. Furthermore, the range of differences in risk perceptions across subgroups varied across hazards. One of the items with the most highly varied ratings was genetically-engineered bacteria.

A subsequent survey (Finucane et al. 2000) found essentially the same pattern of results. However, this time perceptions of the risks of specific food-related hazards were assessed, including the risk of genetically-engineered crops. Again white males were found to have the lowest risk perceptions, with white females and non-white males perceiving about the same risk, and non-white females perceiving the highest risk from genetically-engineered crops (Fig. 1(a)). Importantly, however, this survey oversampled minority groups so that we could get a good idea of how they differed from other groups; when the mean ratings for non-white males and females are shown separately for Hispanic, African-American and Asian subjects, the variation in perceptions across groups and the white-male effect is less distinct. Asian males gave less risky ratings than white males for several food hazards, such as hormones and antibiotics in meat, and gave only slightly higher risk rating than white males for genetically-engineered crops (Fig. 1(b)).

We then looked to see if white males differed from other groups in their world views. Consistent with suggestions of cultural theory that general dispositions orient or motivate individuals (Weber \& Hsee, 2000), we found that compared with other groups, white males are more likely to agree with statements reflecting hierarchical views (e.g. "when a risk is very small, it is okay for society to impose that risk on

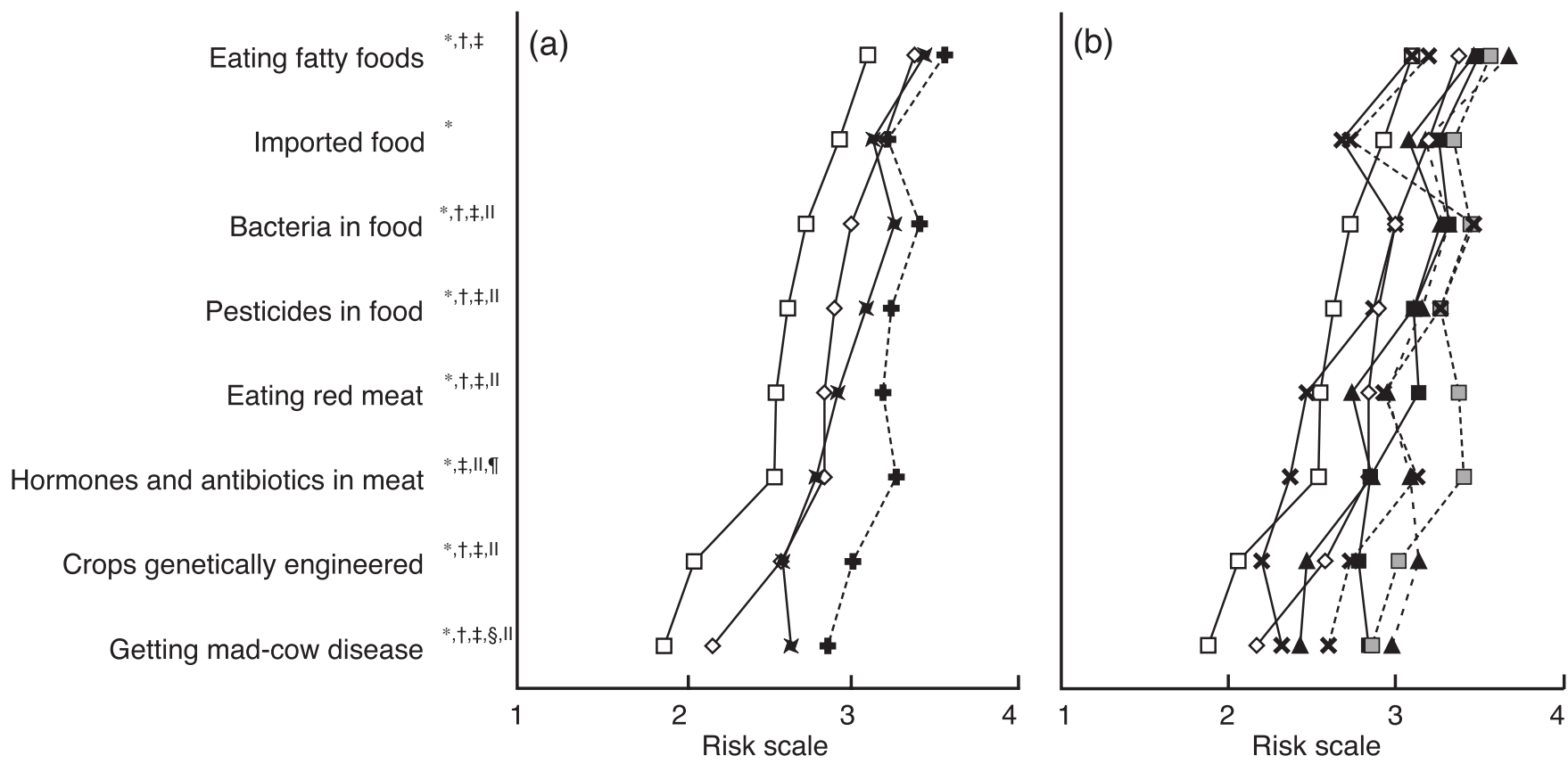

Fig. 1. Mean ratings of perceived risks (1, almost no risk; 2 , slight risk; 3 , moderate risk; 4 , high risk) to the American public for (a) white ( $\square-\square$ ) and non-white $(\chi-\chi)$ males and white $(\diamond-\diamond)$ and non-white (+---+) females (data weighted for race and gender, $n$ 859). Mean values were significantly different for the following comparisons (Tukey post-hoc paired comparisons; $P<0.05$ ): *white males $v$. white females, $\dagger$ white males $v$. non-white males, $\ddagger$ white males $v$. non-white females, $\S$ white females $v$. non-white males, 11 white females $v$. non-white females, 11 nonwhite males $v$. non-white females. (b) White, $(\square-\square, \diamond-\diamond)$, Hispanic $(\boldsymbol{\Delta}-\mathbf{\Delta}, \boldsymbol{\Delta}--\mathbf{\Delta})$, African-American $(\mathbf{\square}-\mathbf{\square}, \square-\square)$ and Asian $(X-X, X--X)$ males and females respectively (data not weighted, $n$ 1170). Results of comparisons are not shown. (Reproduced from Finucane et al. 2000 with permission from Taylor \& Francis Ltd; http://www.tandf.co.uk) 
individuals without their consent') and to disagree with antiindividualistic statements (e.g. to disagree that 'the government should make rules about personal risk-taking activities'). In short, the data suggest that risk perceptions reflect deep-seated values about technology and its impacts on society (see also Barke et al. 1997).

Individual differences in world views are important because they have implications for which approach to safety standards will be supported. For example, a study by Sheehy et al. (1996) suggested that hierarchists feel that the complexity of biotechnology and genetic information undermines their ability to make informed personal decisions. They would prefer mechanisms that draw on the experience of experts to make decisions, rather than rely on their own incomplete knowledge. On the other hand, egalitarians have a strong desire to have information provided to them on which they can base their own personal choices in the marketplace. These individuals also want to be able to make a risk assessment based on their individual beliefs and preferences.

Although most focus-group participants in the Sheehy et al. (1996) study indicated that they would like to be involved in the decision-making process, some suggested that they would be more willing to trust the judgement of others. For many consumers, the judgements they are willing to trust refer mostly to safety standards; for other consumers this trust could be extended to include judgements about ethical considerations of whether a product should be made available on the market.

\section{Conclusions and future directions}

Failing to understand non-scientific perspectives will inevitably lead to a communication and decision-making breakdown. What is important to individuals from different cultures and why it is important to them needs to be made more salient in the GM food debate. This task cannot be done without a systematic examination of values and views of different cultural groups. Furthermore, international agreements that protect vulnerable countries are essential. While global rules should minimize national differences and bring predictability to international trade, they should also still allow for legitimate national differences in concerns and priorities with regard to uptake of complex new technologies.

So where to from here? Both hard-learned experience and considerable research suggest that approaching risk analysis without the involvement of the public is a doomed enterprise. This situation exists because (1) risk decisions are much more likely to be implemented successfully if they have broad public support (National Research Council, 1996), (2) the wisdom relevant to optimal risk management is not confined to scientific specialists and (3) from a normative viewpoint, government should obtain the consent of the governed, who therefore have a right to participate in decision processes (Fiorino, 1990).

Government or industry policy developers and decision makers should take advantage of social science to anticipate and ameliorate conflict. In particular, we need to develop a framework for understanding cross-cultural differences specifically with respect to the complex array of technical and ethical issues raised by new technologies such as GE. Furthermore, we need to begin systematically assessing reliable cross-cultural differences in perceptions, values, attitudes and behaviours regarding GM food, in order to fill in current knowledge gaps and to respond dynamically to issues encountered in international negotiations over GM foods. If community, industry and government stakeholders are to agree on an acceptable level of risk for specific products or technologies, effective and responsible communication is essential. Assessment of, and communication about, risk will only be successful if it is based on a thorough understanding of the psychological and socio-cultural determinants of risk.

\section{References}

Aerni P (1999) Public Acceptance of Transgenic Rice and its Potential Impact on Future Rice Markets in Southeast Asian Countries. Doctoral dissertation thesis, Swiss Federal Institute of Technology, Zurich, Switzerland.

Barke R, Jenkins-Smith H \& Slovic P (1997) Risk perceptions of men and women scientists. Social Science Quarterly 78, 167-176.

Beachy RN (1999) Facing fear of biotechnology. Science 285, 335.

Bruce DM \& Eldridge J (2000) The role of values in risk perception in the GM debate. In Foresight and Precaution, pp. 855-862 [MP Cottam, DW Harvey, RP Pape and J Tait, editors]. Rotterdam, The Netherlands: AA Balkema.

Dake K (1991) Orienting dispositions in the perception of risk: An analysis of contemporary worldviews and cultural biases. Journal of Cross-Cultural Psychology 22, 61-82.

Douglas M \& Wildavsky A (1982) Risk and Culture: An Essay on the Selection of Technical and Environmental Dangers. Berkeley, CA: University of California Press.

Earle TC \& Cvetkovich GT (1995) Social Trust: Toward a Cosmopolitan Society. Westport, CT: Praeger.

Finucane ML, Slovic P, Mertz CK, Flynn J \& Satterfield TA (2000) Gender, race, and perceived risk: The 'white male' effect. Health, Risk and Society 2, 159-172.

Fiorino DJ (1990) Citizen participation and environmental risk: A survey of institutional mechanisms. Science, Technology and Human Values 15, 226-243.

Flynn J, Slovic P \& Mertz CK (1994) Gender, race and perception of environmental health risks. Risk Analysis 14, 1101-1108.

Granot H (1999) Facing catastrophe: Mad cows and emergency policy-making. International Journal of Mass Emergencies and Disasters 17, 161-184.

Grobe D, Douthitt R \& Zepeda L (1999) A model of consumers' risk perceptions toward recombinant bovine growth hormone (rbGH): The impact of risk characteristics. Risk Analysis 19, 661-673.

Hofstede G (1984) Culture's Consequences, p. 277. Newbury Park, CA: Sage.

Klee K (1999) Frankenstein foods? Newsweek 13 September issue, 33-35.

Krimsky S \& Golding D (1992) Social Theories of Risk. Westport, CT: Praeger-Greenwood.

Levidow L (1999) Regulating Bt maize in the United States and Europe: A scientific-cultural comparison. Environment 41, $10-22$.

Losey JE, Rayor LS \& Carter ME (1999) Transgenic pollen harms monarch larvae. Nature 399, 214. 
Marris C (2000) Swings and Roundabouts: French Public Policy on Agricultural GMOs 1996-1999. Report No. 00-02, Guayancourt, France: Cahier du C3ED. Available at http://www.c3ed.uvsq.fr.

National Research Council (1996) Understanding Risk: Informing Decisions in a Democratic Society. Washington, DC: National Academy Press.

Paarlberg R (2000) Genetically modified crops in developing countries: Promise or peril? Environment 42, 19-27.

Sheehy H, Legault M \& Ireland D (1996) Consumers and Biotechnology: A Synopsis of Survey and Focus Group Research. Ottawa, ON: Office of Consumer Affairs, Industry Canada. Available at http://strategis.ic.gc.ca./SSG/ca00921e.html

Shepherd R, Manaras I \& Sparks P (2000) Moral and ethical concerns on genetic modification of foods. In Foresight and Precaution, pp. 849-854 [MP Cottam, DW Harvey, RP Pape and J Tait, editors]. Rotterdam, The Netherlands: AA Balkema.

Slovic P (1987) Perception of risk. Science 236, 280-285.

Slovic P (1992) Perception of risk: Reflections on the psychometric paradigm. In Social Theories of Risk, pp. 117-152 [S Krimsky and D Golding, editors]. New York: Praeger.

Slovic P (1997) Trust, Emotion, Sex, Politics and Science: Surveying the Risk-assessment Battlefield, pp. 277-313 [MH
Bazerman, DM Messick, AE Tenbrunsel and KA WadeBenzoni, editors]. San Francisco, CA: New Lexington.

Slovic P \& Gregory R (1999) Risk analysis, decision analysis, and the social context for risk decision making. In Decision Science and Technology: Reflections on the Contributions of Ward Edwards, pp. 353-365 [J Shanteau, BA Mellers and DA Schum, editors]. Boston, MA: Kluwer Academic.

Tse DK, Lee K, Vertinsky I \& Wehrung DA (1988) Does culture matter? A cross-cultural study of executives' choice, decisiveness and risk adjustment in international marketing. Journal of Marketing 52, 181-195.

Tutangata T (1999) Genetic engineering: The right to say no. Islands Business May issue, 42.

Weber EU \& Hsee CK (1999) Models and mosaics: Investigating cross-cultural differences in risk perception and risk preference. Psychonomic Bulletin and Review 6, 611-617.

Weber EU \& Hsee CK (2000) Culture and individual judgment and decision making. Applied Psychology: An International Review 49, 32-61.

Webster N (1983) Webster's New Twentieth Century Dictionary. New York: Simon \& Schuster. 